\title{
New Interpretation to Disputed Matter of 300 to 400 Degrees Celsius Peak in Hydrogen-detecting Thermal Desorption Spectrum and Potentiality of Hydrogen Generation through this Phenomenon
}

\author{
Yasuhide ISHIGURO, ${ }^{1 * *}$ Shinji OOTSUKA, ${ }^{2)}$ Daisuke MIZUNO ${ }^{3)}$ and Kazuki FUJIMURA ${ }^{11}$ \\ 1) Steel Research Laboratory, JFE Steel Corporation, Kawasaki-cho, Handa, Aichi, 475-8611 Japan. \\ 2) Steel Research Laboratory, JFE Steel Corporation, Kokan-cho, Fukuyama, Hiroshima, 721-8510 Japan. \\ 3) Steel Research Laboratory, JFE Steel Corporation, Minami Watarida-cho, Kawasaki, 210-0855 Japan.
}

(Received on October 21, 2014; accepted on September 1, 2015; J-STAGE Advance published date: November 5, 2015)

\begin{abstract}
This paper provides an answer to the ever-lasting discussion concerning the interpretation of the hydrogen-related peak at 300 to $400^{\circ} \mathrm{C}$ in hydrogen-detecting Thermal Desorption Spectrum which often appears in a hydrogen-introduced steel sample, particularly which has undergone an outdoor exposure or wet/dry cyclic accelerated-corrosion test and/or by acid immersion. Up to now, the focus of the discussion of the peak has been held with respect to whether the reaction is caused by diffusible hydrogen or not. However, the peak does not correspond either to a typical diffusible hydrogen peak at around $200^{\circ} \mathrm{C}$ or to a typical non-diffusible peak at over $400^{\circ} \mathrm{C}$. Rather, the 300 to $400^{\circ} \mathrm{C}$ peak in TDS comes from the formation of hydrogen through a rust-related chemical reaction where iron (III) oxide-hydroxide (oxyhydroxide) of goethite "FeOOH" reacts into iron (III) oxide of hematite " $\mathrm{Fe}_{2} \mathrm{O}_{3}$ ". It should be noted that the origin of $\mathrm{FeOOH}$ comes from rust which is too small to detect and which, even if you are sure that the surface is perfectly smooth and cleaned off by hand-polishing, is not removed due to deeply-rooted and smalldiameter rust particles, and cannot be detected by the naked eye. In addition, following on from this new interpretation of the controversial spectrum, this phenomenon is re-interpreted as a new process to produce hydrogen gas, and the potentiality and the mechanism are also discussed.
\end{abstract}

KEY WORDS: hydrogen; thermal desorption spectrum; TDS; gas chromatograph; rust-based TDS signal; 300 degree celsius to 400 degree celsius peak; diffusible hydrogen; non-diffusible hydrogen; rust; iron oxyhydroxide; iron oxide-hydroxide; goethite; $\mathrm{FeOOH}$; hematite; $\mathrm{Fe}_{2} \mathrm{O}_{3}$; cyclic corrosion test; hydrogen generation.

\section{Introduction}

This paper targets the interpretation of the 300 to $400^{\circ} \mathrm{C}$ peak in Thermal Desorption Spectroscopy (referred as "TDS" below) when measured the hydrogen content in steel. ${ }^{1,2)}$

Hydrogen is still one of important research targets in materials science. Hydrogen embrittlement remains as an unsolved problem. In hydrogen research, the techniques to measure hydrogen have been studied, and a glycerindisplacement-based volumetric method in Japan and a Mercury-displacement-based volumetric method have already been developed, and have been widely used since the early 1970s. ${ }^{3-6)}$ As it is now, Thermal Desorption Spectroscopy ${ }^{3)}$ has come to be commonly used to measure hydrogen content. This paper is concerned with an answer to the puzzle of the 300 to $400^{\circ} \mathrm{C}$ peak in the TDS spectrum.

\footnotetext{
* Corresponding author: E-mail: y-ishiguro@jfe-steel.co.jp DOI: http://dx.doi.org/10.2355/isijinternational.ISIJINT-2014-667
}

Since TDS was introduced to hydrogen research, various steel samples have been evaluated, especially a hydrogenintroduced steel samples. Although it rarely appears in cathodically-charged samples, the peak in TDS is sometimes observed at 300 to $400^{\circ} \mathrm{C},{ }^{7-9)}$ especially in corroded samples through outdoor exposure or wet/dry cyclic acceleratedcorrosion test. In the following report, it should be noted that the TDS is based on the signals measured by using Gas Chromatograph (referred as "GC" below, and "GC-TDS" is also used below for GC-based TDS), unless otherwise stated.

Figure 1 is an example of the 300 to $400^{\circ} \mathrm{C}$ peak, of which there has been no widely-agreed interpretation. This sample is from a corroded sample with hand-polished "clear" surface after corroded in wet/dry cyclic acceleratedcorrosion test of SAE-J2334, ${ }^{10)}$ in which 80 -cycle (80-day) is equivalent to a 9-year on-vehicle corrosion on a public roadway in melting-snow-agent spraying area for an automobile outer (coated) panel, e.g. for door, hood, trunk and so on. 
Figure 2 is a typical TDS spectrum of "a normal steel sample", i.e., as-received steel sheet sample which is annealed without any plating or coating. The area from room temperature (referred as "RT" below) to around $200^{\circ} \mathrm{C}$ has no peaks, and the area at over $400^{\circ} \mathrm{C}$ has hydrogen signals. In contrast, Fig. 3 is another typical example of cathodically-charged steel. Two kinds of hydrogen peaks are observed at both RT to $200^{\circ} \mathrm{C}$ and at around over $400^{\circ} \mathrm{C}$. It is evident that the first peak is a result of hydrogen uptake by cathodic-charging by comparison with Fig. 2, and the peak has been regarded as diffusible hydrogen and is believed to be related to hydrogen embrittlement. In contrast, the spectrum at over 400 to $500^{\circ} \mathrm{C}$ used to be regarded as nondiffusible hydrogen and to be interpreted as independent of hydrogen embrittlement, but the signal is now often regarded only as background at high temperature range in GC-TDS ${ }^{11)}$ and has been considered to be dependent on each GC apparatus itself and/or on each analyzed sample.

The issue in this paper is shown in Fig. 1. The signal of the spectrum at 300 to $400^{\circ} \mathrm{C}$, strictly speaking, does not correspond either to the "diffusible hydrogen"-based peak at RT to $200^{\circ} \mathrm{C}$, or to the "high-temperature background (or non-diffusible hydrogen)" peak at over $400^{\circ} \mathrm{C}$. Although some people have proposed various ways of thinking about the unexplained spectrum, ${ }^{7-9)}$ any comprehensive theories have not been widely acknowledged. Therefore, the objective of this paper is to present a new interpretation of the 300 to $400^{\circ} \mathrm{C}$ signal in TDS. Furthermore, by looking at this phenomenon from a slightly different angle, a new potential for hydrogen generation is advocated through the method of heat-treating corroded steel and/or rust at 300 to $400^{\circ} \mathrm{C}$.

\section{Experimental Procedure and Samples}

First, the technical terms and wording are defined as below. In this paper, three peaks in TDS are topics at issue. Peaks and strong signal areas are categorized as three types. For the sake of convenience, they are called "RT to $200^{\circ} \mathrm{C}$ ", "300 to $400^{\circ} \mathrm{C}$ " and "over $400^{\circ} \mathrm{C}$ " by using temperaturebased terms, because these three categories have strong signals mainly at each temperature range, although some signals sometimes overflow beyond the lower limit and/or the upper limit of each temperature-based wording. In addition, it should be noted that these temperatures do not have any physical meaning. The temperature to appear signals in the TDS spectrum depends on thickness of a sample and the rate of elevating temperature. Therefore, these classifications are expediential, but will be used throughout this paper. As shown in Fig. 1, the important point is that the peak at " 300 to $400^{\circ} \mathrm{C}$ " in TDS has not been yet interpreted correctly. Another point is the wording to describe "TDS spectrum" and "raw chart". The former is used throughout the paper, and the latter is used only in the Discussion section. As shown above in Figs. 1 to 3, the former is the spectrum to plot hydrogen desorption rate as a parameter of temperature. As shown far below in Fig. 14, the latter is the raw data to show thermal conductivity as a parameter of time at gas separation in TDS measurement. The hydrogen content corresponds to the peak at around $0.7 \mathrm{sec}$ in our GC's gas separation system, and the value of integral around the peak is calibrated to the hydrogen desorption rate and each data is plotted as a parameter of sampled temperature in "TDS spectrum".

Experiments in this paper are based on a 2-step approach. The first step is TDS measurement of corroded samples roughly to learn the origin of the hydrogen signal at 300 to $400^{\circ} \mathrm{C}$, and the second step is the investigation to understand the mechanism and to search for the potentiality to generate hydrogen at 300 to $400^{\circ} \mathrm{C}$ by re-interpreting this phenomenon as the reaction to emit hydrogen through heattreatment at 300 to $400^{\circ} \mathrm{C}$.

\subsection{First Step Experiments}

In the first step, steel samples were taken from $2 \mathrm{~mm}$ thick "ordinary" sheet steel (cold-rolled and then annealed without any coatings), and were cut into samples with the dimensions of $2 \mathrm{~mm}$ thick, 50 to $70 \mathrm{~mm}$ long and 12 $\mathrm{mm}$ wide. The chemical composition is typical mild steel $(0.02 \%$ carbon-based $)$ without any intentional additions of alloy elements. The size of samples is smaller than regularly-tested ones in a wet/dry accelerated corrosion test, because the size is limited by the inner diameter of the sample holder in the GC-TDS. The samples were put in a cyclic wet/dry test chamber to control humidity, temperature and test duration. As shown in Fig. 4, the samples were corroded according to the SAE-J2334 ${ }^{10}$ test procedure, which is composed of weekday sessions and holiday sessions: the former is a three-stage wet/dry cycle of salt-dipping at $25^{\circ} \mathrm{C}$ for $15 \mathrm{~min}$, a dry-period in $50 \% \mathrm{RH}$ (Relative Humidity: referred as "RH" below) at $60^{\circ} \mathrm{C}$ for $17.75 \mathrm{~h}$ and a humidperiod at $100 \% \mathrm{RH}$ at $50^{\circ} \mathrm{C}$ for $6 \mathrm{~h}$, and the latter session is to keep at $50 \% \mathrm{RH}$ at $60^{\circ} \mathrm{C}$.

The test samples and conditions are listed on Table 1. The test conditions are (1) as-received (no corroded sample for reference), (2) to (5) for each stage in the 10-day cycle and (6) a heavily-corroded sample to proceed rust-layerdelaminated stage (approximately 80 to 100 -cycle). Only the (2) to (4) samples of 10-day at SAE-J2334 ${ }^{10)}$ corrosion test were kept in liquid nitrogen as soon as it was picked out from the cyclic wet/dry test chamber. Hydrogen in these samples was measured after the rust and corrosion products were removed as thoroughly as possible. One condition of "(5) after humid" in 10-day corroded sample in SAE-J2334 ${ }^{10)}$ test was used for hydrogen measurement of a rust-covered sample for comparison. They were also kept in liquid nitrogen, but the TDS measurement was carried out after the temperature returned to nearly RT. The "(6) heavily-corroded" sample was kept at room temperature inside the acceleration-corrosion test chamber (switched-off) until the hydrogen measurement was started, which is equivalent to keeping at room temperature. Figure 5 shows the appearance after having been corroded in the SAE-J2334 ${ }^{10)}$ corrosion test: (a) a typical example of 10-day corroded sample and (b) samples corroded for over-80days. Since the latter is rust-layer-delaminated and is too fragile to take out as a sheet-formed sample, the rust was powderized and then was used for TDS measurement.

In regard to hand-polishing, a corroded sample was picked out from the liquid nitrogen and then the rust and corrosion products were carefully removed with abrasive papers by hand-polishing being held with a low-temperature-proof glove, and when the sample had been unavoidably heated up 


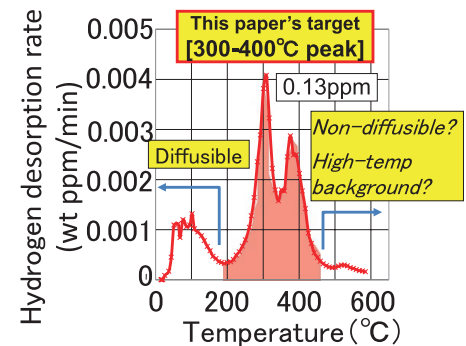

Fig. 1. Typical example of the 300 to $400^{\circ} \mathrm{C}$ peak in TDS spectrum, which is based on a corroded steel sample with hand-polished surface after wet/dry cyclic accelerated corrosion test.

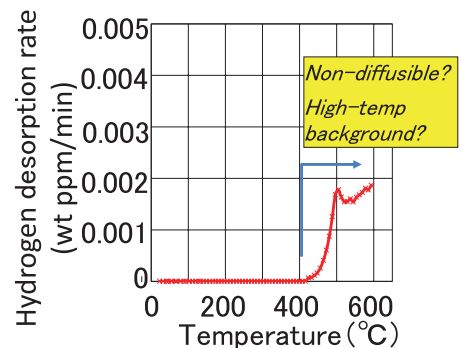

Fig. 2. TDS spectrum of an as-received steel sheet sample which is annealed without any plating or coating.

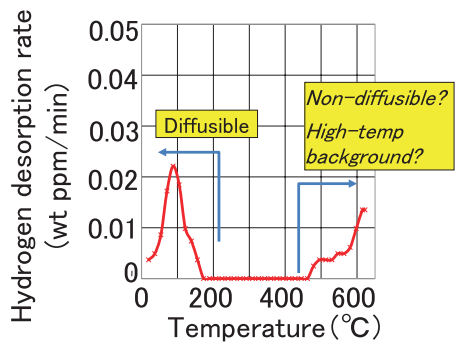

Fig. 3. TDS spectrum of cathodicallycharged steel sample.
SAE J2334 (Corrosion cycle)

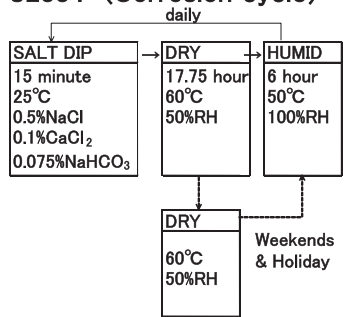

Fig. 4. SAE-J2334 test procedure of wet/dry-cyclic accelerated corrosion test.

(a)

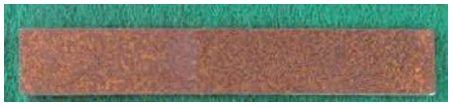

(b) TणU

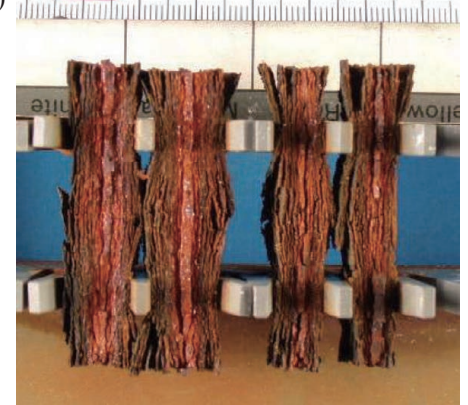

Fig. 5. Typical appearance of as-corroded samples in SAEJ2334's wet/dry cyclic accelerating corrosion test of (a) after 10-day (10-cycle) exposure and (b) over 80-day (80cycle). (a) As-corroded after 10-day (10-cycle) exposure in SAE-J2334. (b) As-corroded after over 80-day (80-cycle) exposure in SAE-J2334.

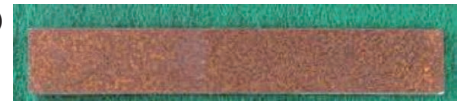

(b)

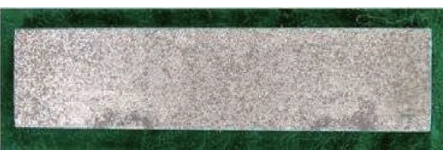

Fig. 6. Typical appearance of (a) as-corroded sample and (b) asrust-removed sample, whose surface looked metallicsheeny and the spots could not be seen, due to frost, during polishing and/or just after polishing for removal of rust and corrosion product. (a) As-corroded after picked from wet/dry cyclic corrosion chamber. (b) As-rust-removed (as thoroughly as possible) after hand-polishing while cooled down below zero ${ }^{\circ} \mathrm{C}$. (a)

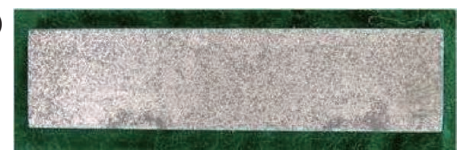

(b)

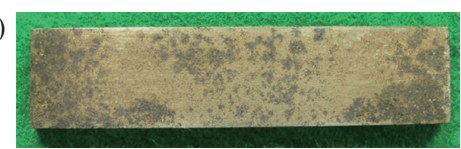

Fig. 8. Typical appearance of (a) before and (b) after TDS measurement. (It should be noted that (a)'s surface looked metallic-sheeny and the spots could not be seen, due to frost, during polishing and/or just after polishing as thoroughly as possible for removal of rust and corrosion product). (a) Before TDS measurement, which is the same as Fig. 6(b). (b) As-finished in TDS measurement.

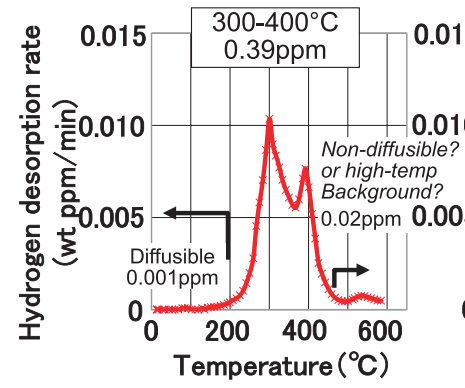

(a)

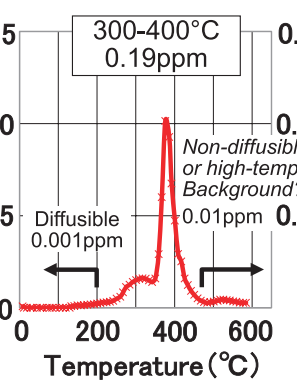

(b)

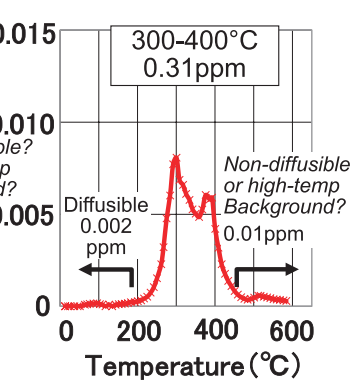

(c)

Fig. 7. GC-TDS spectra of "rust-removed" 10-day exposure samples in SAE-J2334's wet/dry cyclic accelerated corrosion test: (a) after salt dip, (b) after dry stage and (c) after humid stage, which correspond to (2), (3) and (4) in Table 1, respectively. (a) After Salt dip $\left(25^{\circ} \mathrm{C}\right)$. (b)After Dry stage $\left(60^{\circ} \mathrm{C}, 50 \% \mathrm{RH}\right)$. (c) After Humid stage $\left(50^{\circ} \mathrm{C}, 100 \% \mathrm{RH}\right)$. 
Table 1. List of test samples.

\begin{tabular}{|c|c|c|c|c|}
\hline & \multirow{2}{*}{ rust removal } & \multicolumn{3}{|c|}{ SAE-J2334 } \\
\hline & & after dipping & after dry & after humid \\
\hline (1) zero-day (reference) & - & \multicolumn{3}{|c|}{ (as-received of steel sample) } \\
\hline \multirow{4}{*}{10 -day (10-cycle) } & \multirow{2}{*}{ Yes } & (2) GC-TDS & (3) GC-TDS & (4) GC-TDS \\
\hline & & \multicolumn{3}{|c|}{--> kept in Liquid $\mathrm{N}_{2}$ until TDS measurement } \\
\hline & \multirow{2}{*}{ No } & - & - & (5) GC-TDS \\
\hline & & \multicolumn{3}{|c|}{--> kept in Liquid $\mathrm{N}_{2}$ until TDS measurement } \\
\hline \multirow{2}{*}{ (6) $>80$ days } & \multirow{2}{*}{ (No) } & \multicolumn{3}{|c|}{ heavy-corrosion to rust-layer-delaminated } \\
\hline & & \multicolumn{3}{|c|}{--> kept in RT until TDS measurement } \\
\hline
\end{tabular}

to nearly zero ${ }^{\circ} \mathrm{C}$ by friction (rubbing), it was immediately returned to the liquid nitrogen to cool down. The polishing routine was repeated until the surface returned to a metallic sheen as thoroughly as possible. However, samples were so cold that the surface was often covered with frost, no matter how much care was paid to minimize it even by polishing in a dry condition. Figure 6 shows typical surfaces of (a) a corroded sample and (b) a rust-removed sample. In Fig. 6(b), small black spots are now confirmed by sight, but during polishing and/or just after polishing, the surface looked metallic-sheeny and the spots could not be seen, due to frost. The exceptions were rust-free as-received samples ((1) in Table 1), heavily-corroded samples ((6) in Table 1) and one of the 10-day samples (after humid stage: (5) in Table 1).

As for the test condition of TDS, GC-based TDS was used for all the tests in this paper. Each parameter in GC-TDS is listed on Table 2. Gas separation was based on molecularsieve 5A (MS-5A) and hydrogen was detected by the thermal conductivity detector (TCD). The elevating temperature rate was $200^{\circ} \mathrm{C} / \mathrm{h}$ and the sampling time was every $2.5 \mathrm{~min}$. Hydrogen was evaluated as the mass fraction of hydrogen in the steel sample by "mass of desorbed hydrogen/sample weight measured just before TDS". It should be noted that the carrier gas at the GC-TDS was high-purity Argon gas, and that any contaminated components, especially oxygen, did not enter the test chamber through the Argon gas.

\subsection{Second Step Experiments}

Advanced experiments were intended to discover the fundamental mechanism for signals to appear at 300 to $400^{\circ} \mathrm{C}$ in the TDS spectrum, and also to search for a new mechanism for hydrogen generation by re-interpreting the hydrogen signals at 300 to $400^{\circ} \mathrm{C}$ in TDS as a reaction which results in the emission of hydrogen through the heattreatment at 300 to $400^{\circ} \mathrm{C}$.

Although the results in the first-step experiment will be reported later, we would say at this stage that this reaction is related to the unavoidably-remaining rust. Therefore, commercially-available test chemicals of three kinds of rust were prepared for GC-TDS: (1) FeOOH (Goethite), (2) $\mathrm{Fe}_{2} \mathrm{O}_{3}$ (Hematite) and (3) $\mathrm{Fe}_{3} \mathrm{O}_{4}$ (Magnetite), whose catalog-based purities are over $95 \%, 99-101 \%$ and over $95 \%$, respectively. These powdered materials were evaluated by GC-TDS, and one of them was evaluated by X-ray Diffraction (referred as "XRD" below) to know the phase change before/after TDS measurement. Also, the one of rust
Table 2. TDS's test conditions.

\begin{tabular}{c|c}
\hline \multicolumn{2}{c}{ GC-TDS } \\
Gas Chromatography Thermal Desorption Spectroscopy \\
\hline Separation & MS-5A column \\
Detector & TCD (Thermal Conductivity Detector) \\
Flow gas & high-purity Ar \\
Temperature & RT to $600^{\circ} \mathrm{C}$ \\
Elevating Temp rate & $200^{\circ} \mathrm{C} / \mathrm{h}$ \\
Sampling & every $2.5 \mathrm{~min}$ \\
Sample size & $\mathrm{w} 12 \mathrm{~mm} \times \mathrm{L} 50 \mathrm{~mm}$ to $70 \mathrm{~mm} \times \mathrm{t} 2 \mathrm{~mm}$ \\
\hline
\end{tabular}

samples was measured again after the first TDS measurement.

\section{Results}

\subsection{Rust-removed 10-day Exposed Samples in SAE- J2334 Test at First-step Experiment}

Figure 7 shows GC-TDS spectra of (a) after salt dipping, (b) after dry stage and (c) humid stage of 10-day exposed samples in SAE-J2334 test, which correspond to (2) to (4) in Table 1. For your reference, Fig. 1, which has already been mentioned above as a typical example of 300 to $400^{\circ} \mathrm{C}$ peaks, shows 30-day (after humid stage) corroded sample in SAE-J2334 test. Each sample has two peak-based 300 to $400^{\circ} \mathrm{C}$ signals in whose region hydrogen is (a) $0.39 \mathrm{ppm}$, (b) $0.19 \mathrm{ppm}$ and (c) $0.31 \mathrm{ppm}$, respectively. In terms of the signal at RT to $200^{\circ} \mathrm{C}$, which is thought to be diffusible hydrogen, the 10-day samples in Fig. 7 have only tiny signals. This means that the samples do not have any diffusible hydrogen. In terms of the signal at over $450^{\circ} \mathrm{C}$, it is also at a tiny level. This experimental fact indicates two things: (1) The amount of hydrogen which is introduced by cathodiccharging in Fig. 3 is larger than that by the corrosion-based method, and (2) the 300 to $400^{\circ} \mathrm{C}$ signal is dependent on something which is related to the corrosion-based hydrogen reaction, but not to the cathodic-charging. The former fact of (1) is also supported in the literature. ${ }^{12}$ Regarding the latter fact of (2), as one possibility, it can be expected that $\mathrm{Fe}^{2+}$ related reaction may be linked, because cathodic-charging is based only on the reaction of " $\mathrm{H}^{+}+\mathrm{e}^{-} \rightarrow \mathrm{H}$ " to enter hydrogen into steel (electron is provided through potentio/ galvano-stat), but corrosion-based reaction requires both 


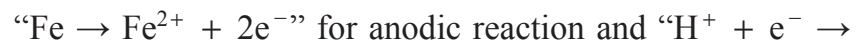
$\mathrm{H}$ " for cathodic reaction, and $\mathrm{Fe}^{2+}$ ion is easily changed into rust and corrosion products.

As mentioned above, when hydrogen in the wet/dry cyclic corrosion test samples was measured by TDS, rust and corrosion products were cleaned off in advance as thoroughly as possible while the test sample was cold enough not to get out as hydrogen gas, in order to know hydrogen content correctly. Figure $\mathbf{8}$ shows the surface appearance at pre- and post-TDS measurement. After TDS measurement, blackish and grayish stains appear and seem to have seeped and spread out. This fact suggests that deeply-rooted rust is formed in corroded samples and cannot be removed completely even by a careful hand-polishing, and that these stains seeps from invisible deeply-rooted spot-like corrosion during TDS measurement. In the next section, the authors focus on rust-related phenomenon.

\subsection{As-corroded Samples (10-day and Over 80-day) in SAE-J2334 Test at First-step Experiment}

Figure 9 shows the GC-TDS spectrum of "rust-covered" as-corroded samples (10-day/after humid stage/(5) in Table 1) in SAE-J2334 ${ }^{10)}$ test, and the appearance before and after TDS measurement. It should be noted that this sample is "as-corroded" without any hand-polishing. The appearance (surface color) changed from reddish brown at pre-TDS (ascorroded) to blackish brown at post-TDS. This suggests that rust is directly related to the signals at 300 to $400^{\circ} \mathrm{C}$ in TDS spectrum, and that the rust on the surface may be changed into a different phase. Figure 10 shows GC-TDS spectrum of over-80day sample in SAE-J2334 ${ }^{10)}$ test ((6) in Table 1 ), and also the appearance of "before TDS". As shown in Fig. 5(b), the over-80day sample was corroded heavily into a multi-layered delaminated form, and so the sample for GC-TDS was broken into a powder-like form when picked out from the comb-like holder. These data in Figs. 9 and 10 mean that rust is the origin of hydrogen at 300 to $400^{\circ} \mathrm{C}$. The hydrogen at 300 to $400^{\circ} \mathrm{C}$ is $7.47 \mathrm{ppm}$ in Fig. 9 and 10.45 ppm in Fig. 10.

However, a careful attention has to be paid to interpret these phenomena. Authors point out some interesting and notable points in Figs. 9 and 10 in comparison to Figs. 1 and 7: (1) the vertical axis in TDS spectra, (2) the definition of hydrogen content (concentration), (3) the one-peak and the two-peak at 300 to $400^{\circ} \mathrm{C}$ region in TDS spectrum.

The first topic is that the vertical axis in Figs. 9 and 10 are about 100 times higher than in Figs. 1, 3 and 7. Since the 300 to $400^{\circ} \mathrm{C}$ signal is based on unavoidably-remaining rust, it can be qualitatively explained that the amount of rust is much smaller inside rust-removed samples in Figs. 1 and 3 than rust-covered samples in Figs. 9 and 10. The second topic is that the definition of hydrogen content in Fig. 10 is different from the ones in any other examples, and it is related to the result at the above first topic in Fig. 10. The hydrogen content is evaluated as the following mathematical formulas of (1) to (3), because the denominator in the formula corresponds to the weight measured just before TDS analysis.

For a rust-removed or rust-free sample in Figs. 1-3 and 7;

hydrogen / steel (1), which is abbreviated to " $\mathrm{H} / \mathrm{S}$ ", because the rust in rustremoved sample is a negligible small quantity.

For a rust-covered sample in Fig. 9;

$$
\text { hydrogen / (steel + rust) }
$$

which is abbreviated to "H/(S+R)".

For a rust sample in Fig. 10 and in yet-undescribed Figs. 11 and 13;

$$
\text { hydrogen / rust }
$$

which is abbreviated to " $\mathrm{H} / \mathrm{R}$ ".

The hydrogen contents in Figs. 9 and 10 are almost the same, but the physical meaning is completely different. Specifically, "H $\mathrm{H}_{\text {Fig. } 9} /\left(\mathrm{S}_{\text {Fig. } 9}+\mathrm{R}_{\text {Fig. } 9)}\right)$ " in Fig. 9 looks the same

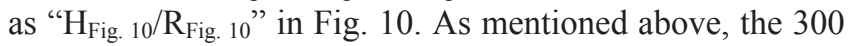
to 400 signal is not related to steel matrix but rather to rust itself, and therefore, it has to be described as " $\mathrm{H}_{\text {Fig. } 9} / \mathrm{R}_{\text {Fig. 9" }}$ " in Fig. 9 for a right interpretation to understand hydrogen generation at 300 to $400^{\circ} \mathrm{C}$, that is, " $\mathrm{H}_{\text {Fig. } 10} / \mathrm{R}_{\text {Fig. } 10 "} \fallingdotseq$ "H $\mathrm{H}_{\text {Fig. } 9} /\left(\mathrm{S}_{\text {Fig. } 9}+\mathrm{R}_{\text {Fig. } 9}\right)$ " < "H $\mathrm{H}_{\text {Fig. } 9} / \mathrm{R}_{\text {Fig. } 9 "}$ ". It should be noted that $\mathrm{S}_{\mathrm{Fig} .9}$ is a larger value. It suggests that the co-existence of steel and rust emits more hydrogen at 300 to $400^{\circ} \mathrm{C}$ than only rust. This topic will be mentioned later again in the following discussion section.

The last topic is that only Fig. 9 shows one-peak TDS spectrum, although other spectra in Figs. 1, 7 and 10 consist of two peaks at $300^{\circ} \mathrm{C}$ and $400^{\circ} \mathrm{C}$. Also, each spectrum in Figs. 7(a) to 7(c) is two-peak-based signal but slightly different each other. Although authors can make mention of these phenomena, we do not have any supporting experimental data to explain it logically and it is an on-going issue for us.

From the results at this section and at the former section, the signal at 300 to $400^{\circ} \mathrm{C}$ in TDS is related to hydrogen generation by rust on the surface of the corroded sample. When we return to the original objective of "what is the signal at 300 to $400^{\circ} \mathrm{C}$ in TDS spectrum, especially of corroded steel (rust-removed) sample?", deeply-rooted rusts unavoidably remain as small-dotted stains in corroded samples and the remaining rust will be the origin of the hydrogen signal at 300 to $400^{\circ} \mathrm{C}$, no matter how thoroughly the rust is removed by hand-polishing.

In the next section, the authors focus on what kind of rust (iron oxide) plays an important role in hydrogen emission, and discuss the potential to generate hydrogen by using rust, that is, by proposing the phenomenon of the hydrogen signal at 300 to $400^{\circ} \mathrm{C}$ in the TDS spectrum as a new method to make hydrogen.

\subsection{TDS Spectra of Rust, and Change of Appearance before/after TDS at Second-step Experiment}

In the following section, as in the above two results sections, it should be noted that the technical term of "TDS spectrum at 300 to $400^{\circ} \mathrm{C}$ " means that strong signals exist mainly at 300 to $400^{\circ} \mathrm{C}$ and some signals overflow at below $300^{\circ} \mathrm{C}$ and $/$ or at over $400^{\circ} \mathrm{C}$.

Three kinds of commercially-available rust were prepared for GC-TDS: (1) Goethite: $\mathrm{FeOOH}$, (2) Hematite: $\mathrm{Fe}_{2} \mathrm{O}_{3}$ and (3) Magnetite: $\mathrm{Fe}_{3} \mathrm{O}_{4}$. The authors could not prepare wustite: $\mathrm{FeO}$, because it is not stable enough to remain as wustite. Figure 11 shows these three GC-TDS spectra and 


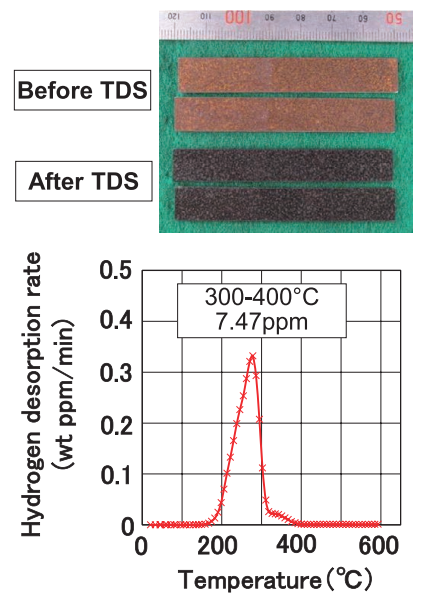

Fig. 9. TDS spectra of "as-corroded (rust-covered)" 10-day exposure sample in SAE-J2334's wet/dry cyclic accelerated corrosion test, and the appearance of before and after TDS measurements, which corresponds to (5) in Table 1.
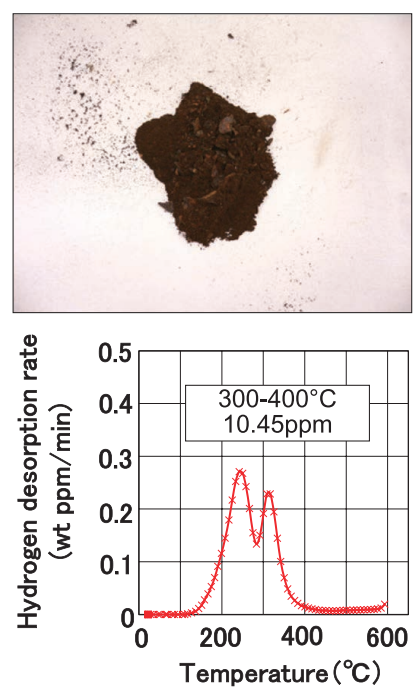

Fig. 10. TDS spectra of over-80days exposure sample (mostly powdered rust) in SAE-J2334's wet-dry cyclic accelerated corrosion test, and the appearance of before TDS measurement, which corresponds to (6) in Table 1.
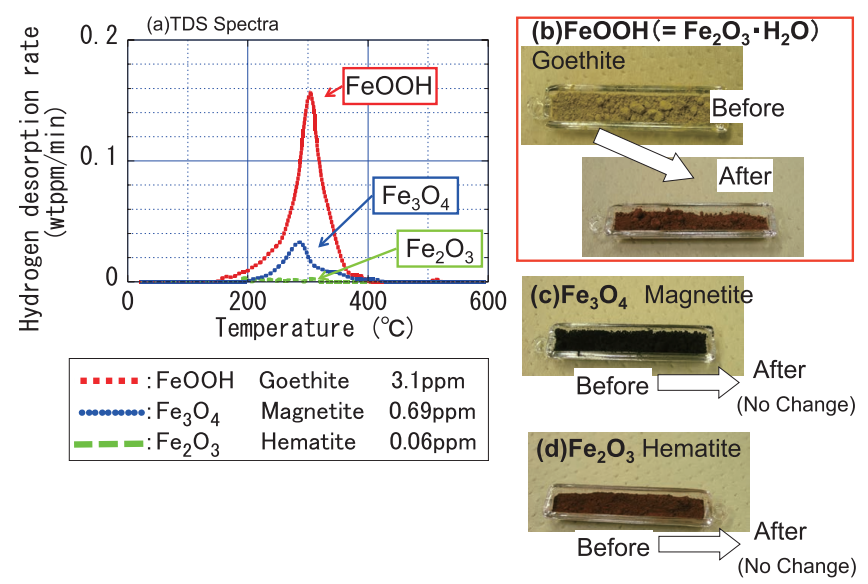

Fig. 11. (a) TDS spectra of $\mathrm{FeOOH}, \mathrm{Fe}_{3} \mathrm{O}_{4}$ and $\mathrm{Fe}_{2} \mathrm{O}_{3}$, and "before/ after TDS measurement" appearance of (b) $\mathrm{FeOOH}$ (Goethite), (c) $\mathrm{Fe}_{3} \mathrm{O}_{4}$ (Magnetite) and (d) $\mathrm{Fe}_{2} \mathrm{O}_{3}$ (Hematite).

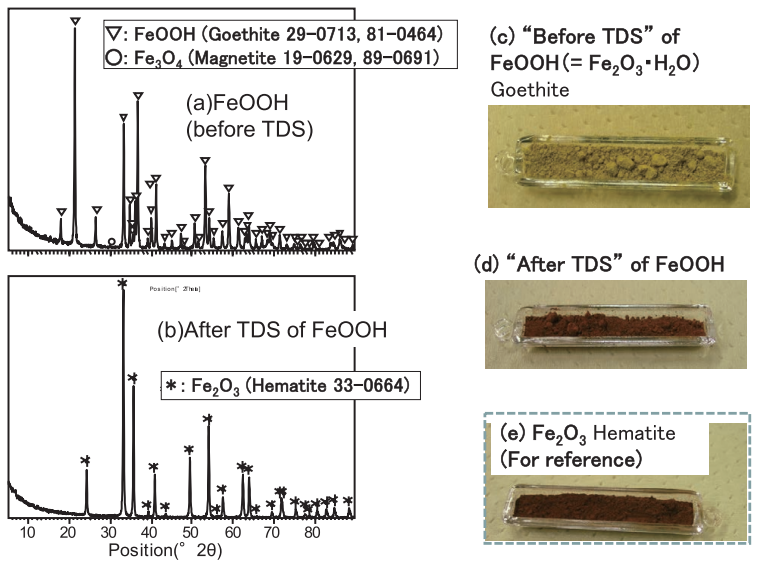

Fig. 12. XRD patterns of $\mathrm{FeOOH}$ as (a) before and (b) after TDS measurement, and these appearance of (c) $\mathrm{FeOOH}$ (before TDS), (d) after TDS of FeOOH and (e) hematite $\mathrm{Fe}_{2} \mathrm{O}_{3}$ for reference. (a) $\mathrm{FeOOH}$ (before TDS). (b) After TDS of $\mathrm{FeOOH}$. (c) "Before TDS" of $\mathrm{FeOOH}$ (= $\mathrm{Fe}_{2} \mathrm{O}_{3} \cdot \mathrm{H} 2 \mathrm{O}$ ) Goethite. (d) "After TDS" of $\mathrm{FeOOH}$. (e) $\mathrm{Fe}_{2} \mathrm{O}_{3}$ Hematite (For reference)

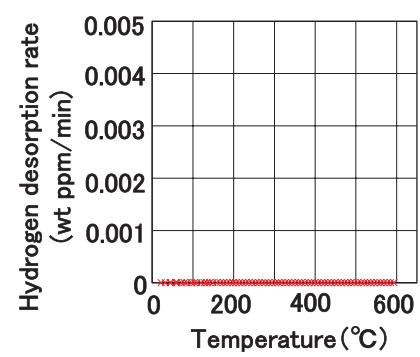

Fig. 13. TDS spectrum of 2nd-measured $\mathrm{FeOOH}$ (precisely speaking, starting material is phase-transformed $\mathrm{Fe}_{2} \mathrm{O}_{3}$ ). (a)

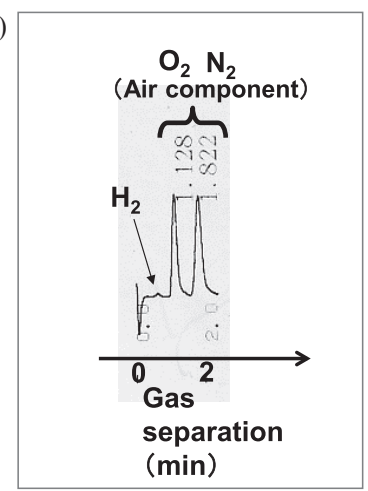

(b)

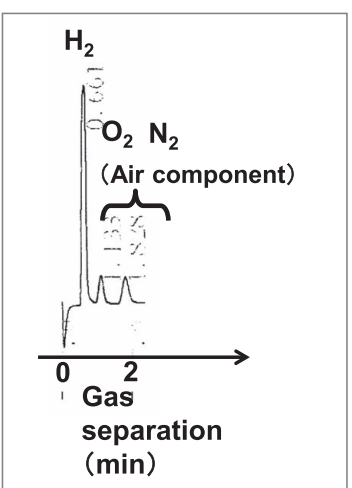

Fig. 14. TDS raw charts of (a) the initial stage (just after a sample is set, and air still remains) and of (b) typical example after over-1hour TDS measurement (air is automatically ejected during measurement). (a): Initial stage (just after a sample is set). (b): Typical example after over lhour TDS measurement (air has been ejected during measurement).

the appearance before and after TDS measurement. Goethite "FeOOH" (over 95\% purity), Magnetite " $\mathrm{Fe}_{3} \mathrm{O}_{4}$ " (over 95\% purity) and Hematite " $\mathrm{Fe}_{2} \mathrm{O}_{3}$ " (99-101\% purity) have the signals at 300 to $400^{\circ} \mathrm{C}$, and the total of hydrogen is 3.1 ppm, $0.69 \mathrm{ppm}$ and $0.06 \mathrm{ppm}$, respectively. The experimental fact proves that the origin of hydrogen at this temperature range is the rust of Goethite "FeOOH". Magnetite and Hematite are not related to the hydrogen generation. The 
data could suggest that Magnetite " $\mathrm{Fe}_{3} \mathrm{O}_{4}$ " has a small effect on hydrogen generation, but commercially-available rust unavoidably has impurities of other rusts (over $95 \%$ purity is only guaranteed) and it is estimated that Goethite "FeOOH" as an impurity may be related to a small amount of hydrogen by Magnetite " $\mathrm{Fe}_{3} \mathrm{O}_{4}$ " as a commercially-available reagent. The other point is the color of "before TDS (as-received)" and "after TDS" in Fig. 11. Goethite "FeOOH" changed from yellowish brown into reddish brown after TDS measurement. Hematite " $\mathrm{Fe}_{2} \mathrm{O}_{3}$ " and Magnetite " $\mathrm{Fe}_{3} \mathrm{O}_{4}$ " did not change in color at "before" and "after" testing. "After TDS" of Goethite "FeOOH" shows the same color of "before/ after TDS" of Hematite " $\mathrm{Fe}_{2} \mathrm{O}_{3}$ ". Therefore, Goethite "FeOOH" was evaluated by XRD to compare the phase of rust "before" and "after TDS" measurement. As shown in Fig. 12, "before TDS" is composed mainly of Goethite "FeOOH" with a small portion of Magnetite " $\mathrm{Fe}_{3} \mathrm{O}_{4}$ ", and "after TDS" consists of Hematite " $\mathrm{Fe}_{2} \mathrm{O}_{3}$ ". The experiment data in Figs. 11 and 12 imply that Goethite "FeOOH" is the origin of the emission of hydrogen at 300 to $400^{\circ} \mathrm{C}$ in TDS spectrum.

Figure 13 shows the second-time measurement by measuring "TDS-measured" Goethite "FeOOH". Judging from Figs. 11 and 12, the first-time measurement is based on the change from Goethite " $\mathrm{FeOOH}$ " to Hematite " $\mathrm{Fe}_{2} \mathrm{O}_{3}$ ", and the second time is based on the measurement of the phasetransformed Hematite " $\mathrm{Fe}_{2} \mathrm{O}_{3}$ ". After the first measurement was finished, the rust sample stayed inside the sample holder about a half day under Argon gas flow until it was cooled down to RT and waited for the second measurement. As shown in Fig. 13, the spectrum is completely flat without any signals, and the color did not change at all, although the appearance is not shown here.

The topic in this paper focuses on the controversial signals at 300 to $400^{\circ} \mathrm{C}$, and our experiment has given an answer to explain the mechanism that hydrogen comes from deeply-rooted stain-like rust (unavoidably remaining tiny spots of rust) of Goethite "FeOOH", no matter how thoroughly the rust on the corroded steel sample is removed by hand-polishing. Precisely speaking, when the rust (Goethite $\mathrm{FeOOH}$ ) is heat-treated at 300 to $400^{\circ} \mathrm{C}$ under Argon flow in TDS, hydrogen is generated. In the following discussion, rust-based hydrogen generation is dealt with as a potential procedure to make hydrogen.

\section{Discussion}

We have already understood in this paper that hydrogen is generated when Goethite "FeOOH" is heat-treated in Argon flowing $\left(\mathrm{O}_{2}\right.$-free $)$ at 300 to $400^{\circ} \mathrm{C}$ inside TDS. Specifically, two kinds of hydrogen generation phenomena have been reported. One is hydrogen generation by Goethite "FeOOH" in Fe-existing environment as the main topic, and the other is hydrogen generation only by commercially-available rust reagent of Goethite "FeOOH" in Fe-free condition as a comparative experiment. In this section, the mechanism and the chemical reaction are discussed below to give a reasonable explanation to the phenomena in Figs. 1, 7, 9-11 and 13. Especially, the quantity and the efficiency of the emission of hydrogen are also discussed, and the potential to make hydrogen is also reported by re-interpreting this phenomenon.

Judging from the graph in Fig. 11, $1 \mathrm{~kg}$ of Goethite "FeOOH" makes just only $3.1 \mathrm{mg}$ of hydrogen on weight basis (when theoretically evaluated on molar basis, $0.2 \% \mathrm{H}_{2}$ generation for $1 \mathrm{~mol}$ of $\mathrm{FeOOH}$ ). In addition, this reaction is not at all a direct decomposition reaction of $\mathrm{H}_{2} \mathrm{O}$, which requires a large amount of energy. However, the generation efficiency in Fig. 11 is rather small. When reviewed from a different viewpoint, even if it is at rather low efficiency, there may be high potentiality to produce hydrogen easily without spending money by using redundant heat and scrap (rust) which lie around in a steelmaking plant. You can see a lot of reddish scrap and energy-filled conditions, for example, steam, fire and heat-exchangers, especially at the upper-stream process of ironmaking, steelmaking and coke furnaces. The authors imagine that such phenomenon may have been already used unconsciously in steel companies. Emitted gas in upper stream of steel plants is collected into a gas holder and used as an energy source to create electricity and heat. It is known that the collected gas is composed mainly of CO gas with a small portion of about $10 \%$ hydrogen. Although nobody may have paid attention, some of the hydrogen may also come from heated iron ore (rust on surface) and heated rusted scrap at the upper-stream process. As another viewpoint, we want to point out the potentiality to improve the efficiency of hydrogen generation when Goethite "FeOOH" and steel co-exists. As explained from the viewpoint of the definition of hydrogen calculation in Eq. (2) in Result 3.2., the rust-covered case in Fig. 9 is at a higher efficiency to make hydrogen than the rust-based powderized case in Fig. 10, which may slightly include iron component, and the latter amount in Fig. 10 shows a higher value than commercially-available test chemical of Goethite "FeOOH" in Fig. 11 (Fe-free condition). The above facts are discussed below in terms of the mechanism of hydrogen generation.

At first, we deny the possibility of well-known Schikorr reaction of (4) below that $\mathrm{Fe}(\mathrm{OH})_{2}$ is heat-treated at 200 to $400^{\circ} \mathrm{C}$ under an $\mathrm{O}_{2}$-free condition into magnetite, water and hydrogen. In our targeting reaction, the starting material is Goethite "FeOOH" and the final material is Hematite " $\mathrm{Fe}_{2} \mathrm{O}_{3}$ ". Therefore, our Hydrogen-generating reaction is completely different from Schikorr reaction. Hydrogen is generated by the phase transformation at 300 to $400^{\circ} \mathrm{C}$ in an $\mathrm{O}_{2}$-free condition (Argon flowing as the carrier gas). The proposed chemical reaction is tentatively given below as (5). The contents of $\mathrm{Fe}$ and hydrogen need to be balanced on the left-hand side and the right-hand side, and the oxygen is balanced on the right-side by using (omit) oxygen molecule, as described in brackets below in (5). From a classical point of view, the reaction from $\mathrm{FeOOH}$ to $\mathrm{Fe}_{2} \mathrm{O}_{3}$ can be also regarded as dehydration reaction and is described below as (9). Furthermore, when iron exists in the reaction system of (9), it has been known as (10) that dehydration-based $\mathrm{H}_{2} \mathrm{O}$ is reduced to $\mathrm{H}_{2}$ by iron and the iron is changed to hematite $\mathrm{Fe}_{2} \mathrm{O}_{3}{ }^{13)}$ Also, a simple $\mathrm{H}_{2} \mathrm{O}$ decomposition of (11) is estimated not to occur at 300 to $400^{\circ} \mathrm{C}$, because the reaction needs as high temperature as 1500 to $2000^{\circ} \mathrm{C}$.

(Schikorr reaction) $3 \mathrm{Fe}(\mathrm{OH})_{2} \rightarrow \mathrm{Fe}_{3} \mathrm{O}_{4}+2 \mathrm{H}_{2} \mathrm{O}+\mathrm{H}_{2} \ldots$ (4) 
(tentative reaction) $\mathrm{FeOOH} \rightarrow 1 / 2 \mathrm{Fe}_{2} \mathrm{O}_{3}+1 / 2 \mathrm{H}_{2}\left(+1 / 4 \mathrm{O}_{2}\right)$

(molar ratio) $1 \mathrm{~mol}$ (rust) $1 / 2 \mathrm{~mol}$ (hydrogen) .... (6)

(expected hydrogen) $100 \mathrm{~g} \quad 100 / 121 / 2 \times 2=0.83 \mathrm{~g} \ldots$ (7)

(in reality in Fig. 11) $1 g(100 g) \quad 3.1 \mu g(310 \mu g) \ldots . .(8)$

(classically defined) $\mathrm{FeOOH} \rightarrow 1 / 2 \mathrm{Fe}_{2} \mathrm{O}_{3}+1 / 4 \mathrm{H}_{2} \mathrm{O}$..

(Fe-oxidation - based reaction) $2 \mathrm{Fe}+3 \mathrm{H}_{2} \mathrm{O} \rightarrow \mathrm{Fe}_{2} \mathrm{O}_{3}+3 \mathrm{H}_{2}$

(Simple $\mathrm{H}_{2} \mathrm{O}$ decomposition) $\mathrm{H}_{2} \mathrm{O} \rightarrow \mathrm{H}_{2}+1 / 2 \mathrm{O}_{2} \ldots$ (

If the above chemical reaction of (5) is correct, oxygen must be observed as well as hydrogen. However, oxygen is observed only as a background level in the GC-TDS raw chart. Figure 14(a) is a typical TDS raw chart of a hydrogenintroduced sample when started TDS measurement. The signal at about $0.7 \mathrm{~min}$ corresponds to hydrogen, and the ones at $1.2 \mathrm{~min}$ and at $2.1 \mathrm{~min}$ correspond to oxygen and nitrogen, respectively. It should be noted that air inevitably remains inside the GC-TDS system, because the sample has been set in the sample holder tube and Air-originated $\mathrm{N}_{2}$ and $\mathrm{O}_{2}$ have remained at the initial stage of TDS measurement. When the TDS measurement proceeds, these air-based components gradually reduce to a background level. TDS is measured at $\mathrm{RT}$ to $600^{\circ} \mathrm{C}$ by sampling every $2.5 \mathrm{~min}$ at elevating temperature rate of $200^{\circ} \mathrm{C} / \mathrm{h}$. As shown in Fig. 14(b), when the sampling at 300 to $400^{\circ} \mathrm{C}$ is carried out, air-based signals have reached to a background level, and such a low level of air-based signals stays intact to the end of measurement. Therefore, the above tentative chemical formula of (5) may look wrong, but the authors think that the reaction of (5) still remains as another possibility to give a logical explanation to hydrogen generation by Goethite "FeOOH" under Fe-free condition, because the Fe-coexisting phenomena in Figs. 1, 7 and 9 can be explained by a classical concept of (9) and (10), but Fe-free phenomena (below a detection limit of Fe in XRD) in Figs. 10 and 11 cannot be interpreted only by this classical viewpoint. As another possibility, even if $\mathrm{O}_{2}$ gas emits in addition to $\mathrm{H}_{2}$ gas, it can be thought that most of hydrogen and oxygen are combined together into water and that the remaining hydrogen is detected and the remaining oxygen may be combined with neighboring Hematite " $\mathrm{Fe}_{2} \mathrm{O}_{3}$ ". Surely, the $\mathrm{O}_{2}$ signal may be rarely confirmed in TDS raw graph, because iron rust often comprises a non-stoichiometric composition and the rust may soak up the $\mathrm{O}_{2}$ into oxide. However, the above explanation still includes a difficult point to explain why $\mathrm{O}_{2}$ peak does not appear strongly, and our theory still remains a matter of discussion. We have not yet had any supporting data to explain the gap between the theory and the reality.

Judging from the discussion so far, the hydrogen generation in Figs. 1, 4, 7, 9, 10 and 11 may be related to two possible reactions of the tentative chemical formulae of (5) and/or the classical concept of "(9) and (10)", although the
Fe-coexisting hydrogen phenomena in Figs. 1, 4, 7 and 9 can be explained (omit) by the above classical concept of (9) and (10). If we persist in this classical concept to the Fe-free hydrogen phenomena in Figs. 10 and 11, we have to consider that even an impurity level of iron below the detection limit in XRD can play an important role to the reaction of (10). However, it would be unlikely to occur it.

The next topic is a quantitative discussion of hydrogen generation by the rust of Goethite "FeOOH" without including iron component. Regarding the above-mentioned chemical reaction and calculated quantity of materials of (6) to (8), we can see that if the chemical formula of (5) is right, hydrogen has to generate $1 / 2 \mathrm{~mol}$ for $1 \mathrm{~mol}$ of $\mathrm{FeOOH}$ in a molar basis. "100 g of FeOOH" corresponds to about $1 \mathrm{~mol}$ $(0.83 \mathrm{~mol})$ of $\mathrm{FeOOH}$ by calculating as $100 /(56+64+1)$, and $1 / 2 \mathrm{~mol}$ of generated Hydrogen corresponds to $0.83 \mathrm{~g}$ by calculating as $100 /(56+64+1) / 2 \times 2$. The weight-based efficiency is theoretically $8.3 \times 10^{-3}$, approximately 0.01 . However, in the real reaction of (8), $3.1 \mathrm{ppm}$ of hydrogen gas is generated, and the weight-based efficiency is $3.1 \times 10^{-6}$. The difference between theory-based calculation and the real measurement is about 4000 -fold. Therefore, it can be thought that most of the hydrogen disappears and/ or the efficiency is much lower than expected in the estimated reaction of (5) or "(9) and (10)". The authors think that most of hydrogen in (5) is combined with oxygen into $\mathrm{H}_{2} \mathrm{O}$, or that most of $\mathrm{H}_{2} \mathrm{O}$ by dehydrating from $\mathrm{FeOOH}$ in (9) still stay as $\mathrm{H}_{2} \mathrm{O}$ and the quantity of hydrogen is limited by the Fe-oxidation-based reaction of (10). As mentioned in the context to compare with Figs. 9 to 11, more hydrogen is confirmed at a rust-related sample with co-existing steel component. It is thought that the classically-recognized Feoxidation-based reaction of (10) occurs after the dehydration reaction of (9).

Although the discussion remains in terms of a key mechanism, we can conclude that the origin of the hydrogen peak at 300 to $400^{\circ} \mathrm{C}$ in GC-TDS is based on the iron rust transformation from Goethite "FeOOH" to Hematite " $\mathrm{Fe}_{2} \mathrm{O}_{3}$ " at 300 to $400^{\circ} \mathrm{C}$ under $\mathrm{Ar}$ gas flow $\left(\mathrm{O}_{2}\right.$-free $)$. Even the remaining stain-like rust, which is difficult to remove completely by hand-polishing, becomes an origin of hydrogen. There is a high possibility that $\mathrm{H}_{2}$ is directly generated by the transformation from Goethite "FeOOH" to Hematite " $\mathrm{Fe}_{2} \mathrm{O}_{3}$ " without any Fe component, in addition to the classically-accepted reaction that dehydrated $\mathrm{FeOOH}$-based $\mathrm{H}_{2} \mathrm{O}$ is changed to $\mathrm{H}_{2}$ under co-existing $\mathrm{Fe}$ component. Some people may say that commercially-available $\mathrm{FeOOH}$ in Fig. 11 and heavily-corroded sample include a small amount of iron component, but we have already checked that the former sample does not show any Fe-based signal at XRD in Fig. 12(a). Therefore, it is reasonable that the reaction to emit hydrogen possibly exists under the condition without any Fe component. As mentioned above, (omit), we are only saying about two possible estimated reactions of (4) or "(9) and (10)". The detailed mechanism in Fe-free environment is an issue in the future.

In addition, the authors want to point out that some similar but inherently-different ideas have been reported, and pick out one example below from the registered Japan patents. ${ }^{14)}$ In similar reports of rust-related hydrogen generation, in many cases, iron-related materials tend to be 
regarded as catalysts for the hydrogen generation. The patent has mentioned a hydrogen emission method by reacting a waste of foamed polystyrene and water under the existence of "iron oxyhydroxide (FeOOH)" or "iron oxide" as a catalyst. Although hydrogen is generated, they say that the origin of hydrogen is based on a waste of foamed polystyrene and water (including chemisorbed water, physisorbed water or crystallization water), but not iron-related material itself. In contrast, our report intrinsically includes a new concept in terms of "FeOOH" as an origin of hydrogen generation through the heat-treatment of 300 to $400^{\circ} \mathrm{C}$, starting from the searching for the origin of the identity of 300 to $400^{\circ} \mathrm{C}$ peak in TDS spectrum. Our interpretation to this phenomenon gives an answer to the ever-lasting 300 to $400^{\circ} \mathrm{C}$ mysterious peak in TDS spectrum, and also suggests a new concept of hydrogen generation by the thermal reaction of iron rust "FeOOH", although the reaction efficiency is rather low and the chemical reaction formula has not logically been described so far.

\section{Summaries}

The following things are summaries in this paper.

(1) It is proved that the TDS peak at 300 to $400^{\circ} \mathrm{C}$ is based on the hydrogen generation by the reaction at 300 to $400^{\circ} \mathrm{C}$ that Goethite "FeOOH" is changed into Hematite " $\mathrm{Fe}_{2} \mathrm{O}_{3}$ " inside a TDS measurement apparatus.

(2) The signal at 300 to $400^{\circ} \mathrm{C}$ in the TDS spectrum often appears in as-corroded sample with corrosion products and corrosion layer, and even in hand-polished corroded sample. The origin of hydrogen is based on deeply-rooted rusts of Goethite "FeOOH" which cannot be removed and unavoidably remain as small dots, no matter how thoroughly it is hand-polished with abrasive papers.

(3) When this phenomenon is re-interpreted as a potential method to make hydrogen by using iron rust of $\mathrm{FeOOH}$ through the thermal reaction of 300 to $400^{\circ} \mathrm{C}$, there may be high potentiality to produce hydrogen but the real efficiency is as low as "1 kg of FeOOH" can generate only "3.1 mg of $\mathrm{H}_{2}$ gas". From another viewpoint of steelmaking plant, especially at the upper-stream process, the heat source of around
300 to $400^{\circ} \mathrm{C}$ exists, and a lot of reddish scrap is relatively easily obtained in the whole area of a steelmaking factory. The authors think of FeOOH-based hydrogen generation as another potential way to get hydrogen easily through the thermal treatment of 300 to $400^{\circ} \mathrm{C}$.

(4) As for the efficiency to emit hydrogen, the coexistence of iron rust of $\mathrm{FeOOH}$ and steel is more highly efficient than only $\mathrm{FeOOH}$. In the coexistence case, in addition to an estimated rust-transformation-based direct reaction to emit hydrogen from Goethite "FeOOH" to Hematite " $\mathrm{Fe}_{2} \mathrm{O}_{3}$ " (chemical reaction of (5)), it is reasonable that a widely-acknowledged $\mathrm{H}_{2} \mathrm{O}$-reduction-based reaction occurs preferentially or simultaneously with the above direct reaction, that is, dehydrated $\mathrm{FeOOH}$-based $\mathrm{H}_{2} \mathrm{O}$ is changed into $\mathrm{H}_{2}$ when co-existing with $\mathrm{Fe}$ and $\mathrm{Fe}$ is oxidized to $\mathrm{Fe}_{2} \mathrm{O}_{3}$.

(5) The comprehensive reaction to emit hydrogen from the rust has not completely described as chemical formulae. It still remains an on-going subject.

\section{REFERENCES}

1) Y. Ishiguro, S. Otsuka, D. Mizuno and K. Fujimura: CAMP-ISIJ, 26 (2013), 974

2) Y. Ishiguro, S. Otsuka, D. Mizuno and K. Fujimura: CAMP-ISIJ, 26 (2013), 975.

3) JIS Z3113-1975: 1975, Method for Measurement of Hydrogen Evolved from Deposited Metal, JISC.

4) IIW Doc. II A-474-79: 1997.

5) ISO 3690: 2012, Determination of Hydrogen Content in Ferritic Steel Arc Weld Metal.

6) JIS Z 3118-2007: 2007, Method for Measurement of Amount of Hydrogen Evolved from Steel Welds.

7) S. Sakashita, E. Akiyama, K. Tsuzaki and S. Matsuyama: Tetsu-toHagané, 88 (2002), 849.

8) T. Fukuzumi, K. Kobayashi, S. Komazaki and T. Misawa: Tetsu-toHagané, 92 (2006), 58.

9) K. Suzumura and S. Nakamura: J. Jpn. Soc. Civil Eng., A65 (2009), 776.

10) Society of Automotive Engineers (SAE): SAE-J2334, Surface Vehicle Standard, J 2334 Laboratory Cyclic Corrosion Test, SAE, Warrendale, PA, (1998).

11) H. Suzuki and K. Takai: ISIJ Int., 52 (2012), 174.

12) Institute of Iron and Steel: Advances in Delayed Fracture Solution, Institute of Iron and Steel, Tokyo, (1997).

13) T. Kitou, Y. Osaka, G. Yokota, N. Kobayashi, M. Morioki and Y. Umeda: J. Jpn. Soc. Ener. Res., 33 (2012), No. 2, 10.

14) H. Watabane and K. Hanyu: Method and Device for Producing Hydrogen from Resin Waste, Japan Patent, JP2003-119474A, (2003). 